\title{
O TRABALHO DOCENTE COM CONHECIMENTOS GRAMATICAIS NA ESCOLA: ENTRELUGAR OU NORMATIVISMO?
}

\author{
LETÍCIA MELO GIACOMIN ${ }^{1}$
}

\author{
Universidade Federal de Santa Catarina \\ Programa de Pós-Graduação em Linguística \\ Rua Eng. Agronômico Andrei Cristian Ferreira, s/n - 88040-900 \\ Florianópolis, SC - Brasil \\ leticia giacomin@hotmail.com
}

\begin{abstract}
Resumo. Este artigo tematiza os desafios do trabalho docente com ensino de conhecimentos gramaticais. Apresenta recorte de pesquisa que acompanhou egressos de um Curso de Letras de Universidade do Sul do país. A questão de pesquisa que move o artigo é: Como profissionais egressos de Curso de Letras compreendem/operam com o ensino e a aprendizagem de conhecimentos gramaticais na disciplina de Lingua Portuguesa na Educação Básica?, objetivando problematizar e descrever analiticamente os fazeres pedagógicos relacionados ao ensino de conhecimentos gramaticais efetivamente operacionalizados em aulas de Lingua Portuguesa ministradas por esses professores. Os resultados apontam que tais egressos, em se tratando de gramática na esfera escolar, parecem oscilar em um entrelugar ou um normativismo.
\end{abstract}

Palavras-chave: ensino de conhecimentos gramaticais; normativismo; professores de Língua Portuguesa.

\begin{abstract}
This article discusses the challenges of teaching work with teaching grammar knowledge. Presents a research cut that accompanied graduates of a Course of Portuguese Language of a southern University. The research question that moves the article is: How do graduates of the Course of Portuguese Language understand/operate with the teaching and learning of grammatical knowledge in the subject of Portuguese Language in Basic Education?, aiming to problematize and analytically describe the pedagogical practices related to the teaching of grammar knowledge effectively operationalized in Portuguese Language classes taught by these teachers. The results show that students, when it comes to grammar in the school sphere, seem to oscillate in a between place or in a normativism.
\end{abstract}

Keywords: teaching of grammatical knowledges; normativism; Portuguese Language teachers.

\footnotetext{
${ }^{1}$ Doutoranda no Programa de Pós-Graduação em Linguística da Universidade Federal de Santa Catarina.
} 


\section{INTRODUÇÃO}

As abordagens dos conhecimentos gramaticais no ensino e as implicações desses conhecimentos na formação do estudante parecem ainda demandar atenção, mesmo após mais de duas décadas da publicação dos PCNs (BRASIL, 1998) e de importantes discussões no campo de estudos do ensino de língua materna. O ensino de conhecimentos gramaticais vem sendo há muito tempo objeto de reflexões e de críticas e constitui, a nosso ver, um dos maiores desafios enfrentados pelos professores, mesmo por aqueles que, há pouco, iniciaram sua atuação na carreira e, em tese, não estariam 'contaminados' pela tradição gramatiqueira escolar. Os professores nos parecem muito seguros daquilo que não devem fazer em sala de aula, mas sentem dificuldade em compreender, então, o que deve ser feito, acarretando, com base em Giacomin (2013), o movimento chamado por Correia (2013) de entrelugar, no qual professores acabam por proceder a um 'mix' teórico, recorrendo à gramática normativa, em aulas focadas na norma-padrão.

O entendimento acerca dessa necessidade move este artigo, cujo tema assim se delimita: os desafios do trabalho docente com o ensino de conhecimentos gramaticais no Ensino Fundamental. Desse modo, a questão de pesquisa a que buscamos responder é: Como profissionais egressos de Curso de Letras compreendem/operam com o ensino e a aprendizagem de conhecimentos gramaticais na disciplina de Língua Portuguesa na Educação Básica? Em convergência com essa questão, o objetivo deste artigo é problematizar e descrever analiticamente os fazeres pedagógicos relacionados ao ensino de conhecimentos gramaticais que foram efetivamente colocados em prática nas aulas de Língua Portuguesa ministradas pelos professores participantes da pesquisa de Giacomin (2013).

Aqui, retomaremos dados do estudo de Giacomin (2013), que se trata de dissertação de Mestrado defendida em tal ano e que teve como objeto o ensino de conhecimentos gramaticais nas aulas de Língua Portuguesa de sexto a nono anos em escolas públicas municipais e, como participantes, seis egressos do Curso de Letras Português de universidade do Sul do país, dentre os quais dois atuavam na docência e foram acompanhados ao longo de três bimestres letivos, tendo sido entrevistados e participado de roda de conversa ao final do estudo; os outros quatro egressos participaram do estudo sob forma de entrevistas. O critério para a seleção desses participantes foi a obtenção de índice de aproveitamento acadêmico igual ou superior à nota sete - a média para aprovação era nota seis -, não tendo havido reprovações em disciplinas ao longo da graduação, de modo a lidar com um grupo que, em tese, formou-se atendendo inteiramente às exigências estabelecidas pelo Curso. A metodologia utilizada partiu dos pressupostos da pesquisa qualitativa por ser um modelo flexível e que é passível de se ajustar aos objetivos de pesquisa pelo fato de não impor modelos específicos de geração e prévias categorias de análise dos dados, conforme explica Mason (1996). Além disso, tratou-se de estudo de caso do tipo etnográfico (ANDRÉ, 1995) por envolver, entre outras características, o trabalho em campo, no qual o pesquisador se aproxima das pessoas, vivencia as situações e se situa no local e nos eventos escolares. O processo de geração de dados operacionalizou-se por meio de observações diretas, notas em diário de campo, entrevistas, pesquisa documental e roda de conversa, e teve como norte a questão de pesquisa mencionada e o objetivo de pesquisa como orientação, e a análise deles se deu a partir de uma filiação histórico-cultural - essa filiação se justifica por ser fundamentobase da Proposta Curricular da rede pública estadual a cuja unidade da federação 
corresponde a universidade em foco, assim como é fundamento-prevalente da rede pública municipal da capital desse mesmo Estado.

Isso posto, este artigo organiza-se em duas seções de conteúdo. Na primeira delas, problematizamos o desafio que constitui o ensino e a aprendizagem de Língua Portuguesa, principalmente no tocante aos conhecimentos gramaticais, ancorados teoricamente em autores amplamente conhecidos por suas discussões acerca deste ideário educacional, que entendemos serem base para o exposto na segunda seção, em que discutimos tanto a adesão ao normativismo quanto entrelugar e o esvaziamento conceitual do ensino e da aprendizagem de conhecimentos gramaticais nas aulas de Língua Portuguesa em se tratando dos mencionados egressos.

\section{DESAFIOS PARA CONSOLIDAR UMA ABORDAGEM DE ENSINO FOCADA NAS PRÁTICAS SOCIAIS}

O ensino de Língua Portuguesa nas escolas tem sido questionado há anos, tendo em vista que o foco da aula de Português, ao que parece, em muitos casos, são os conteúdos oriundos da abordagem da gramática normativa e, por isso, as aulas se pautam em procedimentos que não valorizam a linguagem como forma de ação social. A discussão acerca da necessidade de mudança quanto ao ensino de Língua Portuguesa em nosso país tem, pois, longa data e ganha especial destaque a partir da década de 1980 (BRITTO, 1997), mas seguramente os desafios para que um novo olhar se institua ainda não parecem ser tão fortemente significativos. De acordo com Geraldi (1997), importa abandonar a 'reprodução' de conhecimento em nome da 'apropriação' de conhecimentos. Para isso, não precisamos banir o trabalho com os conhecimentos gramaticais na escola, e sim fazer deles fonte para reflexões. Assim, cabe ao professor de Língua Portuguesa provocar no aluno a consciência de que a língua pode ser entendida como um corpus dinâmico, que se transforma de acordo com o passar do tempo e das necessidades da sociedade.

Parece-nos amplamente sabido hoje que trabalhar com conhecimentos gramaticais nas escolas implica pensar na língua em uso, visando ao desenvolvimento da capacidade discursiva do sujeito para que seja capaz de se movimentar e se inserir nas diferentes esferas da atividade humana.

É admissível supor que, idealmente, o ensino da Gramática não visa fazer com que o sujeito decore uma nomenclatura, mas que domine procedimentos de análise que lhe permitam pensar sobre a língua e ampliar suas possibilidades de uso. (BRITTO, 1997, p. 125)

Entendemos que, na contemporaneidade, já seja de certo modo consensual que discutir a forma como os conhecimentos gramaticais têm tido lugar historicamente na escola não significa denegar a gramática, implicada na formação do usuário da língua nos diferentes gêneros discursivos: "[...] o conhecimento gramatical é, pois, um conhecimento necessário para aquele que se dedica ao estudo da língua e ao seu ensino" (GERALDI, 1996, p. 72). Trata-se de uma questão complexa que torna a metodologia desse ensino uma das mais recorrentes preocupações dos professores de Língua Portuguesa. Como abordar os conhecimentos gramaticais, em uma perspectiva dinâmica, de modo que efetivamente assumam a condição que lhes cabe nos processos de ensino e aprendizagem, 
ou seja, estar a serviço da potencialização das habilidades de leitura e escuta, de produção textual oral e escrita, tal qual propõe a literatura da área atualmente (GERALDI, 1996; ANTUNES, 2003; BRITTO, 1997)?

Parece-nos unânime a compreensão de que a aula de Língua Portuguesa, boa parte das vezes em que é evocada, tende a remeter a 'domínio de regras', conjunto de categorias que determinam o 'bem falar e escrever'. Muitos, dentre os professores, ainda hoje, consideram que um 'bom ensino' deve ser aquele que permita que os alunos escrevam e falem corretamente a partir das normas vigentes na gramática normativa, pois desse modo irão 'escrever melhor' (BRITTO, 1997). Se desde a década de 1980 profissionais de Letras (professores e pesquisadores) tentam criar alternativas para o que se considera a 'crise do ensino', como explicita Faraco (2006), tal quadro mudou pouco porque ainda não foi possível eliminar "o normativismo e a gramatiquice" (FARACO, 2006, p. 11, grifos do autor).

Pelo seu caráter conservador, impositivo e excludente, o normativismo e a gramatiquice são parte intrínseca de todo um conjunto de conceitos, atitudes e valores fundamentalmente autoritários, muito adequados ao funcionamento de uma sociedade profundamente marcada pela divisão e exclusão social. (FARACO, 2006, p. 11, grifos do autor)

E para que haja uma mudança nesse âmbito é necessário que aconteça também uma mudança no campo sociocultural. Para Faraco (2006, p. 11),

o desafio maior está, portanto, na reconstrução do nosso imaginário sobre a língua, promovendo, nessa área, um reencontro do país consigo mesmo. Nesse sentido, deverá estar na pauta, por exemplo, a superação crítica do fosso linguístico que o século XIX criou artificial e arbitrariamente entre nós como parte de um anacrônico projeto de sociedade apenas branca e europeizada. Em outras palavras, a questão da língua terá de ser percebida também em sua dimensão histórica.

Nessa dificuldade para consolidar efetivamente um novo olhar sobre o ensino da língua, é preciso considerar que, historicamente, a escrita no ensino canônico - e, por implicação, a gramática normativa - tende a constituir instrumento de dominação das elites, considerando que o acesso - ainda que restrito - das camadas populares aos bens culturais socialmente legitimados é fenômeno recente, que remonta ao século XIX; esse acesso das camadas populares à cultura escrita canônica parece ser um movimento de via única: não reverberam, na escrita, os saberes e as especificidades culturais dessa classe. Sob a lógica desses olhares, o contexto social e o econômico são fatores intrinsecamente imbricados no processo educacional, o qual, por vezes, mostra-se alheio a especificidades de tais contextos. A escola, como instituição, acaba, então, acentuando as diferenças sociais; o próprio discurso da escola converge historicamente com a identidade das elites escolarizadas em detrimento de particularidades das classes socioeconomicamente marginalizadas.

Um maior domínio acerca de como os recursos linguísticos são agenciados em favor dos diferentes projetos de dizer dos enunciadores, nas mais variadas esferas da atividade humana, é seguramente fator de inclusão sociocultural, sobretudo em se tratando de alunos oriundos de segmentos economicamente marginalizados e, por implicação, 
alijados dos processos de escolarização plena. Dominar de modo mais efetivo as diferentes leituras, os diferentes usos da escrita e da oralidade, monitorando os recursos linguísticos por meio dos quais os sentidos se materializam, são comportamentos fundamentais no mundo atual (GERALDI, 1997).

Antunes (2003; 2007; 2009), escrevendo assumidamente para professores da Educação Básica, registra sua preocupação com o fato de a aula que tematiza conhecimentos gramaticais resumir-se a passar regras no quadro-negro e pedir para que os alunos as copiem, em uma exercitação destituída de sentido. O resultado tende a ser desastroso: notas insatisfatórias e aprendizado quase nulo. Posturas como essas normalmente afastam os alunos da empatia pelo estudo da língua materna na escola. É amplamente consensual que o ensino da norma sem objetivos interacionais não traz grandes possibilidades de desenvolvimento linguístico aos alunos; eles precisam ter contato com as modalidades da língua em uso, experienciá-las. Os processos de ensino e aprendizagem precisam ser reflexivos, deve-se crer na capacidade do aluno para que não se acabe em um ensino mecanicista, abstrato e sem sentido. Sob essa perspectiva, cabe ao professor transformar o ensino dos conhecimentos gramaticais em algo interessante para o aluno, mostrandolhe uma gramática na textualização, que referencie o uso efetivo da língua, sugere a autora. Sob essa perspectiva, o ensino dos conhecimentos gramaticais não pode se distanciar da realidade prática, tornando-se um amontoado de regras sem função; não pode ser visto como algo à parte, isolado, sem relação com outras vertentes da aula de Língua Portuguesa, como a produção textual. Sobre essa questão, escreve Faraco (2006, p. 25-26):

Só existe sentido em estudar gramática [...] se conseguimos romper radicalmente com o modelo pedagógico medieval de ensino de língua. [...] o estudo de conteúdos gramaticais faz sentido quando feito de forma contextualizada e funcional [...], feito de modo a destacar a flexibilidade estrutural da língua e a consequente riqueza expressiva à disposição dos falantes: nenhuma língua é um conjunto rígido de expressões. Sua organização estrutural se caracteriza - sendo como é produto e processo histórico - como um vasto universo de variedades expressivas, de formas alternativas, o que implica antes escolha que submissão.

Segundo esse conjunto de proposições e compreensões, importa que o ensino de tais conhecimentos gramaticais seja visto como suporte, base para o de outras áreas do português, no tocante à interação entre os sujeitos, para o uso efetivo da linguagem. Dessa maneira, pensar que o ensino de tais conhecimentos seja decadente e que nada se possa fazer para reverter essa situação é lidar de modo conformista; ou de modo radical, quando a ideia é abolir o ensino de conhecimentos gramaticais na escola.

A questão maior não é ensinar ou não ensinar gramática. Por sinal, essa nem é uma questão, uma vez que não se pode falar nem escrever sem gramática. A questão maior é discernir sobre o objeto do ensino: as regras (mais precisamente: as regularidades) de como se usa a língua nos mais variados gêneros de textos orais e escritos. (ANTUNES, 2003, p. 88, grifos da autora)

Sob essa perspectiva, o papel da escola é ensinar a norma culta da língua - concebida no sentido que lhe dá Faraco (2008) - e instigar os sujeitos para uso efetivo dela nas 
interações em que esse uso lhes é requerido. Não se trata de negar a legitimidade do ensino de conhecimentos gramaticais, e sim de perceber que tal ensino só faz sentido quando no interior de uma disciplina que o constitui e só pode funcionar como instrumento efetivo se os que deles se apropriarem forem capazes de conhecer sua referencialidade.

\section{EM BUSCA DE COMPREENDER O ENSINO DE CONHECIMENTOS GRAMATICAIS EMPREENDIDO POR PROFESSORES DE LÍNGUA PORTUGUESA}

A interpretação dos dados gerados ao longo do estudo de Giacomin (2013) nos leva à reflexão acerca das lacunas no processo de ensino e aprendizagem de conhecimentos gramaticais. Mesmo tendo cursado um amplo conjunto de disciplinas sobre teoria gramatical durante sua formação universitária, sob diversas abordagens, mas especialmente com foco sistêmico imanentista, a maior parte dos participantes da pesquisa em questão parece associar gramática à norma, tanto que estes não adjetivam gramática quando fazem menção ao termo e em alguns casos essa associação é diretamente estabelecida com manual de gramática. Sob uma perspectiva sistêmica, a língua se constitui de léxico mais gramática, e exatamente essa constituição é objeto de boa parte - talvez a maior - do currículo do Curso em questão. Quando egressos, porém, os participantes parecem sentir-se liberados de adjetivar gramática, tomando-a como sinônimo de norma. O enunciado a seguir, de licenciado egresso, interlocutor em Giacomin (2013), parece icônico desse tipo de representação - a adjetivação 'normativa', entre colchetes, é da pesquisadora:

(1) $[. .$.$] na primeira escola em que dei aula fui contratada como$ professora de gramática [normativa]; então, essa prática me fez ter bastante base. O que sei até hoje foi porque tive que dar aula de gramática [normativa], foi prática mesmo, coisa que aprendi estudando sozinha. (GIACOMIN, 2013, p. 216)

Mais um enunciado nesse diapasão, agora de participante codificado como NVES:

(2) Ele [o professor] deve entender que muitas vezes a gramática [normativa] possui regras arbitrárias e não dá conta do sistema linguístico que possuímos, e, portanto, não pode ser encarada como verdade. (GIACOMIN, 2013, p. 274)

Em tais enunciados, a necessidade de adjetivação complementar, na análise de dados empíricos, do nome gramática, de modo a delinear sua especificidade conceitual - uma intervenção recorrente em Giacomin (2013) e extensiva a todos os participantes daquele estudo -, sinaliza para o que entendemos ser um 'apagamento' no tangente a representações acerca desse mesmo conceito respectivas à teoria linguística formalista estudada na graduação. Em (2) essa dissociação parece de tal modo flagrante que gramática é tida como normativismo e tomada distintamente de "sistema linguístico que possuímos", o que necessariamente remete à gramática internalizada. Como suscitam (1) e (2), em se estando na esfera escolar, gramática parece tornar-se isomórfica a prescritivismo - quer como conteúdo de ensino quer como artefato manual didático, o 'livro de gramática normativa'. 
Quando o enfoque são os conhecimentos gramaticais, os egressos parecem denotar 'vontade de' fazer um trabalho voltado para a língua em uso e para o sujeito em interação, mas sentem-se despreparados para tal, e disso emerge a prevalência de dois comportamentos docentes: 1) ora se dá o enfoque categorial sistêmico ou a sistematização da gramática normativa ${ }^{2}$; ou, em contrapartida, dá-se 2) uma total ausência do trabalho com os conhecimentos gramaticais.

(3) Após a chamada e organização da turma, BTPG monta o retroprojetor para a aula do dia, que se baseará no power point "Pensando a gramática que usamos". Logo no primeiro slide constam as classes gramaticais, e a professora pergunta aos alunos quais dessas classes eles já haviam estudado e de quais se lembravam. Os alunos, então, começam a responder todos ao mesmo tempo, e a professora explica que começarão pelo substantivo. Ao fim da explicação acerca dos substantivos, BTPG pergunta: "por que menina é um substantivo?"; os alunos não parecem saber a resposta, e a sala fica em silêncio. Um aluno, ao tentar responder à pergunta, diz que tinha "a ver com pronome, né?", confundindo as classes gramaticais. Os alunos, no início, mostram-se bastante entusiasmados com o retroprojetor, ansiosos em ver os slides, mas depois parecem dispersos. (GIACOMIN, 2013, p. 136)

Nesse caso em específico, entendemos que a sistematização de conhecimentos gramaticais em categorias é o enfoque da aula, e a explicação consiste em detalhamento de conceitos gramaticais classificatórios, que parecem não significar para os alunos. Podemos, no entanto, observar que o título dado aos slides - 'Pensando a gramática que usamos' - sinaliza para essa 'vontade de'. Encaminhamentos como esse também surgem em:

(4) BTPG inicia as atividades passando no quadro-negro um exercício, composto por algumas frases isoladas, referente à aula na qual tratou das classes gramaticais, e pede para que os alunos o copiem e respondam a ele em seus cadernos. "Procure substantivos, artigos e adjetivos nas frases: Naqueles tempos, a vida em SP era tranquila. / Os mitos procuravam explicar a origem do universo e a criação do homem. / O mito é considerado verdadeiro e tem uma função religiosa". A correção foi feita de forma oral: a professora aponta a palavra e os alunos dizem a classe à qual a palavra pertence. Quando, na terceira frase, um aluno questiona de que classe era o "do", a professora adia, para outro momento, a explicação de que ali também havia um artigo, mas estava aglutinado à preposição, adiamento possivelmente justificado em razão da complexidade do todo em discussão. (GIACOMIN, 2013, p. 137)

(5) Alguns dias depois das explicações acerca das classes gramaticais, BTPG retoma o conteúdo, com mais alguns exercícios no quadro-

\footnotetext{
${ }^{2}$ Distinguimos aqui enfoque categorial sistêmico de sistematização da gramática normativa. Pelo primeiro, entendemos o sistema abstrato das formas linguísticas (VOLÓCHINOV, 2009 [1929]) - um enfoque categorial nas classes e nas funções gramaticais nos limites de uma abordagem estruturalista; pelo segundo, entendemos a chamada norma-padrão, como a define Faraco (2009), um enfoque em questões como concordância, regência e colocação pronominal. Estamos cientes de que a segunda implica a primeira, mas quer nos parecer que existem diferenças entre elas.
} 
negro, no mesmo esquema dos anteriores, com enfoque classificatório. Poucos alunos respondem e a professora os chama um a um pelo nome para darem suas respostas, mas, de modo geral, eles não sabem classificar as palavras das frases. Um dos alunos diz que na frase "Nas minhas lembranças de infância, meus primos estão presentes", a palavra "primos" é um adjetivo, sugerindo não ter entendido os conceitos que BTPG havia explicado há algumas aulas. Ao final da correção, a professora retoma a matéria, lendo em voz alta para os alunos as anotações/explicações que eles já têm registrada em seus cadernos. $\mathrm{O}$ enfoque é conceitual. (GIACOMIN, 2013, p. 137)

Em comportamento próximo ao de BTPG, mas agora sistematizando a gramática normativa, em atividade convergente com práticas sociais de referência (HALTÉ, 2008 [1998]) da 'tradição escolar', OGLR também faz uso do projetor durante aula em que trata de concordância nominal, expondo regras básicas de concordância em outras línguas (inglês e espanhol) e diferenças entre a concordância na fala e na escrita, conforme expostos na vinheta a seguir.

(6) OGLR inicia a aula com o uso do projetor para trabalhar concordância nominal com os alunos. Os slides começam com imagens divertidas e um diálogo criativo que incita à explicação do conteúdo e chamam a atenção dos alunos para a matéria. Quando, porém, OGLR mostra diferenças na concordância entre as línguas espanhola e inglesa, os alunos perdem o foco na aula. O slide acerca das diferenças entre a concordância verbal oral e escrita é mostrado pela professora. A ideia dessa comparação entre as línguas parece interessante a nós, possivelmente porque lidemos com mais de uma língua e conheçamos sua configuração metalinguística; talvez não valha o mesmo para os alunos. No momento da explicação, a professora lê os exemplos que constam nos slides e procede assim até o final da apresentação em power point. Em seguida, pede para que os alunos copiem em seu caderno a "Regra básica para concordância nominal escrita do Português: A concordância nominal é o acordo entre o nome (substantivo) e seus modificadores (artigo, pronome, numeral, adjetivo) quanto ao gênero (masculino ou feminino) e o número (singular ou plural). Exemplo: As aulas de Português são divertidas". Após os alunos terem copiado a regra e o exemplo, a professora os lê em voz alta e, em seguida, pede que copiem um exercício: "coloque no plural a seguinte frase, circulando os substantivos e indicando os adjetivos com substantivos correspondentes: o cartaz da menina está na parede da escola". (GIACOMIN, 2013, p. 138-139)

Em nossa compreensão, essa atividade busca um foco em que regras e nomenclaturas não sejam tomadas apenas na abstração sistêmica. Os exemplos, porém, parecem não ter tido sentido aos alunos, que não souberam como fazer o exercício. Este pode ser também um episódio sinalizador da coexistência de uma 'consciência' acerca da necessidade de trabalhar com a língua nas práticas sociais, como uma realidade axiologicamente saturada (FARACO, 2009), e, por outro lado, uma recorrência, em alternância, às regras tomadas quase em sua imanência; ou seja, a 'vontade de', mas o 'despreparo para'. Com base no estudo de Correia (2013) e, embora atentos ao possível mascaramento da tradição normativista, arriscamos reafirmar aqui a nossa interpretação: essas professoras estariam no entrelugar, havendo, de um lado, a ancoragem histórico-cultural sobre a qual se 
assentam documentos oficiais de ensino de Língua Portuguesa e boa parte da literatura da área contemporaneamente - do que emerge a 'vontade de' - e, de outro, a 'tradição escolar' do ensino imanentista de conhecimentos gramaticais - o que decorreria, em boa medida, do 'despreparo para'. Escreve Correia (2013, p. 211, grifos da autora):

\begin{abstract}
Parece-nos, aqui, haver um entrelugar: um movimento rumo a um agir pedagógico pautado nos grandes eixos do ideário histórico-cultural, mas ainda não consolidado de fato. Temos inferido que a sincretização dos saberes cientificos com os demais saberes que têm lugar na esfera escolar talvez insularize as ações pedagógicas nesse entrelugar; ou seja, possivelmente não chegaremos ao 'final' desse movimento, de modo a elidir a preposição entre e vislumbrar o novo lugar.
\end{abstract}

Segue mais uma vinheta sinalizadora dessa coexistência: (7) "Após a aula de concordância nominal, OGLR marca uma prova com os alunos cujo conteúdo é: substantivo, adjetivo, concordância nominal, coerência textual e interpretação de texto" (GIACOMIN, 2013, p. 139). Essa posposição dos itens - os quais parecem tomados como correlatos entre si, apesar de suas diferenças de base teórica - mostra-se como exemplar dessa alternância entre enfoques distintos: classes gramaticais (enfoque sistêmicocategorial) ao lado de regras de concordância (enfoque normativista) e de coerência (transição para um olhar textual com base em uma Linguística Textual ainda em um estágio inicial (CHAROLLES, 1978). Tais docentes parecem movimentar-se em um ire-vir, no que entendemos ser a mencionada vontade de 'fazer o novo' e uma dificuldade para isso, na busca de 'pontos de apoio' no que é 'consagrado' na esfera escolar. Nessa oscilação, acabam por aglutinar pressupostos de entendimento e trabalho com a linguagem completamente antagônicos.

Em nossas interações com BTPG, pareceu-nos evidente sua formação de base históricocultural, o que se revela sempre que o enfoque das aulas são leitura e produção textual, quando, porém, lhe toca focalizar conhecimentos gramaticais, essa ancoragem parece não encontrar suporte teórico-metodológico que lhe dê segurança para arriscar uma ação que fuja à tradição escolar, conforme ela própria afirma na vinheta a seguir.

(8) Quando parte para a gramática eu fico sempre assim pisando em ovos, "ai será que é isso, será que não é". Porque, na verdade, quando eu saí do terceirão e logo vim fazer Curso, eu estranhei que não tinha gramática normativa, e tem aquela cobrança nossa mesmo, quando a gente ingressou: "Mas não tem gramática, como vai ser depois quando eu for dar aula?" Parece que foi deixado o tempo todo isso de lado, só que a gente chega na escola e é uma outra realidade, mas a gente não tem essa segurança, não tem essa formação, falta. (GIACOMIN, 2013, p. 150)

Quanto à preocupação conceitual, BTPG e OGLR informam que a cobrança pelo que chamam 'sistematização' parte, muitas vezes, dos próprios alunos, os quais, apesar de não gostarem desse tipo de aula, questionam se o que estão aprendendo é Português sempre que partem para uma abordagem focada na textualização. Trata-se, a nosso ver, da reverberação do "normativismo e da gramatiquice" (FARACO, 2006), entranhados ainda no senso comum. 
(9) É que eles já estão habituados com aula de Português [cujo foco recai na sistematização de regras e nomenclaturas gramaticais], então às vezes tinha algumas aulas [quando não havia essa sistematização] que os alunos: "Ah, professora, isso é aula de Português?" [...] É que na verdade eles não gostam [da sistematização das regras e nomenclaturas gramaticais], mas eles acham que aula de Português é isso, estão habituados a isso de aulas anteriores; então, quando a gente foge disso eles acham estranho. (GIACOMIN, 2013, p. 151)

Entendemos haver prevalência do ideário da língua como objeto social nas representações de BTPG e OGLR quando refletem sobre o processo de elaboração didática em aulas de Língua Portuguesa, mas, na materialização dessas elaborações, reiteramos, esse ideário coexiste com concepções imanentistas quando o assunto são conhecimentos gramaticais. Ainda que se trate de docentes que revelem aprofundamento em suas discussões sobre os fazeres pedagógicos e cuja trajetória acadêmica se mostra substantivamente rica, os titubeios no trabalho com conhecimentos gramaticais parecem objeto de sua própria insatisfação.

Especificamente sobre gramática, os excertos a seguir decorrem de respostas dadas quando os entrevistados foram questionados sobre o que eles entendiam por gramática, $o$ que compreendemos profundamente relacionado à concepção de língua: (10) "Gramática é um conjunto de regras que rege sobretudo a escrita padrão" (GIACOMIN, 2013, p. 156) - aqui, gramática, para NVES, vincula-se à normativismo. Vale a mesma interpretação para: (11) "Gramática, para mim, é uma espécie de dicionário de norma-padrão: poucos fazem uso, ou não sabem usar [...]" (GIACOMIN, 2013, p. 156). Já no excerto (12), de novo o enfoque na escrita: (12) "Eu me apoio e penso que é uma forma de escrever a língua, como a língua se comporta" (GIACOMIN, 2013, p. 156). Parecem-nos ainda pouco claras concepções sobre o conceito de gramática especificamente, havendo forte vínculo com o normativismo, ou seja, ênfase em uma das várias acepções do conceito (POSSENTI, 2000), como sugerem também os excertos a seguir: (13) "Gramática é o que os alunos não querem aprender, e os professores não querem ensinar. [...] Gramática é uma reunião de convenções repletas de exceções que nos norteiam na lida com a língua escrita" (GIACOMIN, 2013, p. 156); e ainda: (14) "Uma normatização, um padrão. Acho que seja necessária, mas ela puramente não deve ser o foco do ensino nas aulas de Língua Portuguesa" (GIACOMIN, 2013, p. 156). Em (15) a seguir, enunciação de BTPG, parecenos mais nítida uma concepção de gramática como conhecimento internalizado (POSSENTI, 2000):

(15) Não sei, a normalização de algumas regras, no caso, para não... É que, talvez se não tivesse a gramática determinada, então as pessoas não conseguiriam se entender por que seria tudo cada um na sua maneira. Acho que gramática é essa questão da normalização, de tentar, não uniformizar, mas tentar deixar o mais claro possível. (GIACOMIN, 2013, p. 156)

Quando questionados sobre como o professor de Português deve lidar com a gramática em sala de aula, alguns a relacionaram com o texto como o ponto de partida para o início do trabalho com conhecimentos gramaticais, no que parece ser um movimento de...para; ou seja, uma dissociação entre textualização e sistema. 
(16) Sempre que eu trabalho com gramática penso duas hipóteses: 1 O aluno deve estar em contato com texto e relacioná-lo com o cotidiano para que se possa passar de interpretação textual para análise textual. 2 - Da mesma forma que, para entrar em um parque, um indivíduo necessite conhecer as regras antes de entrar, ele precisa conhecer a gramática, o funcionamento da língua para fazer a análise em texto. (GIACOMIN, 2013, p. 157)

(17) [Devemos trabalhar gramática] sempre aliada ao texto, partindo do texto para explorar, dentro dele, as muitas formas de se utilizar a normapadrão, os contextos, para depois trazer as regras de funcionamento. (GIACOMIN, 2013, p. 157)

Já no excerto (18) a seguir, OGLR, docente atuante, registra que considera interessante que esse texto seja o dos próprios alunos, e que se parta daí para que se trabalhe com os conhecimentos gramaticais; além disso, expõe que, partir do uso da própria língua é uma opção, não enfocando as regras decoradas, e sim a funcionalidade delas no texto. $\mathrm{Na}$ sequência, excerto (19), BTPG manifesta-se também em favor de partir das necessidades dos próprios alunos para, assim, pensar o trabalho com a gramática. Entendemos haver, aqui, intenção de que o estudante desenvolva a reflexão acerca da língua, para que a textualização não se embase em regras aleatoriamente expostas aos alunos, que é o que ocorre não raras vezes no ensino de conhecimentos gramaticais.

(18) O professor deve sempre partir do uso da língua. É interessante refletir alguns aspectos gramaticais com o próprio texto dos alunos; eu noto que eles veem mais sentido em aprender ou com textos mesmo. Por exemplo, vai estudar pronome, ver no texto como eles funcionam, qual a função deles. Mas não decoreba, tento não focar nisso, mais no uso. (GIACOMIN, 2013, p. 157)

(19) Mas eu acho que partir da necessidade mesmo dos alunos, ter esse olhar sensível para ver o que está faltando ali, o que tem de equívoco ou problema para daí pensar... (GIACOMIN, 2013, p. 157)

Em interação durante roda de conversa, uma das professoras participantes de pesquisa manifesta também sua insegurança por não saber qual a melhor maneira de proceder nas aulas em relação ao ensino de conhecimentos gramaticais, tendo dúvidas quanto ao que deve ser ensinado e ao que deve ser apenas de conhecimento do professor, como concebem Franchi, Negrão e Müller (2006), ao enunciarem que deve haver diferença naquilo que é ensinado pelo professor em relação aos conhecimentos gramaticais e aquilo que ele precisa saber como conhecimento próprio quanto à gramática, pois o professor deve saber e conhecer a gramática normativa para dispor de uma boa base para ser capaz de discorrer acerca de tudo isso com seus alunos. Este excerto registra claramente a dificuldade para lidar com saberes científicos na elaboração didática e inconsistências na formação epistemológica.

(20) Eu pessoalmente tenho dificuldade em perceber o que são regras que são importantes os alunos terem conhecimento e o que é nomenclatura perda de tempo, saber os nomes e tal, o que é perda de tempo e o que é interessante. [...] Para mim é muito difícil trabalhar com a questão da gramática, reconhecer o que pode levar o aluno a fazer um uso melhor da língua, principalmente as regras da variedade padrão, que 
são diferentes do uso coloquial, que são importantes na escrita e o que é perda de tempo. [...] daí eu já fico "ai, meu Deus, o que é interessante, futuro do subjuntivo, futuro do indicativo e tal? Será que eu tenho que focar nas nomenclaturas? Não, tenho que focar no uso, mas, poxa, o nome também não é importante?" Então eu fico nessa questão, assim... (GIACOMIN, 2013, p. 158)

Inquietou-nos sobretudo que nenhum dos participantes desta pesquisa mencionou conhecimentos gramaticais como tendo espaço substantivo em suas aulas, tendo em vista que tais assuntos, quando trazidos à tona, tendem a ser trabalhados como a gramática normativa prevê, além disso, como já mencionado anteriormente, os egressos não se sentem preparados para trabalhar esses temas com propriedade e de forma a fazer sentido aos alunos. Desse modo, o espaço destinado ao ensino de conhecimentos gramaticais em sala de aula fica significativamente reduzido, como explicitam OGLR: (21) "Vai depender da situação, mas não é o meu foco [referindo-se ao espaço destinado ao ensino de conhecimentos gramaticais em suas aulas]" (GIACOMIN, 2013, p. 188) e BTPG: (22) "Deixa eu ver... acho que, sei lá, de 10 a $20 \%$, se fosse colocar em porcentagem. [...]" (GIACOMIN, 2013, p. 188). Assim, o mencionado espaço privilegiado para leitura, oralidade e produção textual escrita possivelmente seja ocupado por abordagens que não tocam em tais recursos gramaticais e lexicais agenciados em favor dos projetos de dizer (BAKHTIN, 2000 [1979]) de autores, de falantes, de leitores e auscultadores, em uma perspectiva epilinguística. E, se a aula de Língua Portuguesa tangencia tais recursos, que aula efetivamente é essa? Seria uma aula em que leitura e produção textual são estudadas com base apenas no senso comum?

Entendemos que o trabalho com conhecimentos gramaticais não deve ser denegado da sala de aula, como discorre Geraldi (1997); deve-se, todavia, fazer desse trabalho fonte de reflexões sobre a língua: haveria como refletir sobre a leitura, a oralidade e a produção textual escrita fora da língua? O conhecimento gramatical é necessário aos que enveredam pelo estudo e ensino da língua, já o conhecimento normativo explícito não o é para se aprender a ler e escrever com propriedade.

\section{CONSIDERAÇÕES FINAIS}

A partir do exposto e da interpretação dos dados, compreendemos que tais participantes sinalizam, em suas enunciações e ações, uma percepção de língua no que chamamos aqui, com base em Correia (2013), de uma possibilidade de entrelugar: ora parece se manifestar uma concepção de língua como prática social, com ancoragem histórico-cultural, levando em consideração os sujeitos na sua singularidade e historicidade (GERALDI, 2010) e remetendo a bases epistemológicas de propostas para fundamentos com ensino de conhecimentos gramaticais que vemos em estudiosos como Britto (1997), Faraco (2008) e Geraldi (1997); ora parece se manifestar uma concepção de língua sistêmica/imanentista ou uma concepção psicologista, objetos da crítica de Volóchinov (2009 [1929]), que as nomeia respectivamente como abordagens objetivista e subjetivista. Assim, surgem dois comportamentos em oscilação: ora se dão enfoques - e/ou representações - categorialsistêmicos, ora se manifestam ensaios de uma ação de base enunciativista, mas sem muitas consequências, na alternância entre uma concepção lógico-gramatical e uma concepção retórica (FARACO, 2001). 
Em Giacomin (2013), fomos a campo na expectativa de encontrarmos ações e representações ainda muito focadas no normativismo; o que encontramos foram manifestações pontuais desse normativismo, na oscilação do entrelugar já mencionado. $\mathrm{Na}$ absoluta maioria das aulas que vivenciamos e na maior parte das entrevistas que realizamos, os participantes desta pesquisa focam na leitura e na produção textual, mas o fazem em uma dissociação com o ensino de conhecimentos gramaticais. Os professores estudam teorias gramaticais diversas, mas, quando lhes é requerido explicitamente lidar com gramática, recorrem à gramática normativa, em aulas focadas na norma-padrão.

A partir dessa interpretação, não há como estranharmos que, mesmo após mais de vinte anos de estudos nesse campo (GERALDI, 1997; BRASIL, 1998), parece-nos que o que ocorre - quando ocorre - são focos nos conceitos teóricos dos quais os participantes de pesquisa se apropriaram durante a graduação, em objetificações ou reificações, e não uma elaboração didática que visibilize a análise linguística tomada como a concebem Geraldi (1997) e os PCNs (BRASIL, 1998). Dessa forma, convergimos com o exposto em Correia (2013), concluindo que os participantes do estudo de Giacomin (2013) podem se encontrar num entrelugar quanto a concepções de língua, coexistindo, por um lado, a ancoragem histórico-cultural e, por outro, as práticas sociais de referência fundadas na 'tradição escolar' do ensino normativista dos conhecimentos gramaticais.

Assim, em nosso entendimento, esta discussão coloca luz no desafio que constitui o trabalho com o ensino de conhecimentos gramaticais nas aulas de Língua Portuguesa com base em uma concepção de língua como prática social, ainda uma problemática em nosso sistema educacional, que atinge tanto escolas públicas como particulares. Resultados obtidos com tal pesquisa visibilizam quase que o desaparecimento - quando não o foco normativista - do ensino de conhecimentos gramaticais nas aulas de Língua Portuguesa no Ensino Fundamental. Ressaltamos que não intentamos apontar erros ou acertos, objetivamos, na realidade, contribuir com estudos na área, principalmente voltados para a Linguística Aplicada, com a intenção de que se construam inteligibilidades que, em alguma medida, incidam sobre problemas linguísticos socialmente relevantes.

\section{REFERÊNCIAS}

ANDRÉ, M.E.D.A. de. Etnografia da prática escolar. 17ª ed. Campinas: Papirus, 1995.

ANTUNES, I. Língua, texto e ensino: outra escola possível. São Paulo: Parábola, 2009.

ANTUNES, I. Muito além da gramática: por um ensino de línguas sem pedras no caminho. São Paulo: Parábola, 2007.

ANTUNES, I. Aula de português: encontro e interação. São Paulo: Parábola, 2003.

BAKHTIN, M. Estética da criação verbal. 4a. ed. São Paulo: Martins Fontes, 2000 [1979].

BORGES NETO, José. Ensaios de Filosofia da Linguística. São Paulo: Parábola, 2004.

BRASIL. SEF. Parâmetros curriculares nacionais: terceiro e quarto ciclos do ensino fundamental: língua portuguesa. Brasília: MEC/SEF, 1998.

BRITTO, L.P.L. A sombra do caos: ensino de língua X tradição gramatical. São Paulo: Mercado de Letras, 1997.

CHAROLLES, M. (1978) Introdução aos problemas da coerência dos textos. Em: GALVES, Charlote et. al. (Orgs.). O texto: leitura e escrita. São Paulo: Pontes, 1997. p. 33-90.

CORREIA, K. Diretrizes para análise da escritura: uma abordagem histórico-cultural. Tese. Doutorado em Linguística, Programa de Pós-Graduação em Linguística, Universidade Federal de Santa Catarina, Florianópolis, SC, 2017. 
CORREIA, K. O ato de dizer na esfera escolar: reverberações do ideário histórico-cultural no ensino da produção textual escrita. Dissertação. Mestrado em Linguística. Programa de PósGraduação em Linguística, Universidade Federal de Santa Catarina, Florianópolis, SC, 2013.

FARACO, C.A. Linguagem e discurso: as ideias linguísticas do Círculo de Bakhtin. São Paulo: Parábola, 2009.

FARACO, C.A. Norma culta brasileira: desatando alguns nós. São Paulo: Parábola, 2008.

FARACO, C.A. Ensinar X Não ensinar gramática: ainda cabe essa questão? Calidoscópio, Rio Grande do Sul, v. 4, n. 1, p. 15-26, jan/abr 2006.

FARACO, C.A. Pesquisa aplicada em linguagem: alguns desafios para o novo milênio. Delta, São Paulo, v. 17, n. especial, p. 1-9, 2001.

FRANCHI, C.; NEGRÃO, E.V.; MÜLLER, A.L. Um exemplo de análise e de argumentação em sintaxe. Em: POSSENTI, Sírio. (Org.). Mas o que é mesmo "gramática"? São Paulo: Parábola, 2006. p. 126-151.

GERALDI, J.W. Portos de passagem. 4a . ed. São Paulo: Martins Fontes, 1997.

GERALDI, J.W. Linguagem e ensino: exercícios de militância e divulgação. Campinas: Mercado das Letras, 1996.

GIACOMIN, Letícia Melo. Os conhecimentos gramaticais na escola: 'regras' de um ensino sem regras. Dissertação. Mestrado em Linguística, Programa de Pós-Graduação em Linguística, Universidade Federal de Santa Catarina, Florianópolis, SC, 2013.

HALTÉ, Jean F. O espaço didático e a transposição. Fórum Linguístico, Florianópolis, v. 5, n. 2, p. 117-139, jul./dez. 2008 [1998].

MASON, J. Qualitative researching. London: Sage Publications, 1996.

POSSENTI, S. Por que (não) ensinar gramática na escola. São Paulo: Mercado das Letras, 2000.

SAUSSURE, Ferdinand de. Curso de Linguística Geral. São Paulo: Cultrix, 2000 [1916].

VOLÓCHINOV, V.N. Marxismo e filosofia da linguagem: problemas fundamentais do método sociológico na ciência da linguagem. São Paulo: Editora 34, 2017 [1929].

Artigo recebido em: out. de 2019.

Aprovado e revisado em: nov. de 2019.

Publicado em: dezembro de 2019.

Para citar este texto:

GIACOMIN, Letícia Melo. O trabalho docente com conhecimentos gramaticais na escola: entrelugar ou normativismo? Entremeios [Revista de Estudos do Discurso, ISSN 2179-3514, online, www.entremeios.inf.br], Seção Estudos, Programa de Pós-Graduação em Ciências da Linguagem (PPGCL), Universidade do Vale do Sapucaí (UNIVÁS), Pouso Alegre (MG), vol. 20, Especial, Dossiê "Língua, discurso e trabalho na contemporaneidade", p. 111-124, dez. 2019. DOI: http://dx.doi.org/10.20337/ISSN2179-3514revistaENTREMEIOSvol20pagina111a124 